\title{
Encouraging Results From DDS Urine Analysis Among Registered Leprosy Patients in the Wangas, Kenya: An Exception That Challenges the Rule
}

\author{
HAN HUIKESHOVEN AND IMAN BIJLEVELD
}

Royal Tropical Institute, Mauritskade, Amsterdam, The Netherlands

\begin{abstract}
From previous research among the Wangas (Kenya), it appeared to be the standard of medical services, and in particular the leprosy fieldworker's approach, rather than sociocultural factors, which accounts for failure of leprosy control.

The present investigation adds weight to these findings. Urine samples were taken from 39 patients of one highly reputable leprosy fieldworker, and analysed for DDS/creatinine ratios. Comparison with data from elsewhere demonstrates their scrupulousness in weekly DDS-taking at home.
\end{abstract}

\section{Introduction}

In 1975 to 1976 a sociological research project was carried out in Western Province, Kenya, in an attempt to better understand the rapid turnover of registered leprosy patients in the West Kenya Leprosy Control Project (WKLCP).

Erratic attendance appeared to put effective control out of the question. Although before researchers entered the field it was believed that social and cultural variables would account for patients' problematic behaviour, eventual findings demonstrated that the failure of control efforts were more easily attributed to short-comings in the quality of those administering leprosy care services than to consequences of the values system adhered to by those receiving these services (Varkevisser, 1977; Bijleveld, 1976, 1977). This conclusion was reached in part after a study in the Wangas of patients and expatients of 2 leprosy fieldworkers (LFW) of vastly different calibre, one a model of conscientiousness and the other somewhat lax in job performance. There was virtually no defaulter problem at any of the superior leprosy fieldworker's clinics. Some irregularity of attendance did occur, but of acceptable proportions. The fieldworker's success must first and foremost be ascribed to his holding of clinics on schedule without fail, and his ability to demonstrate personal concern for the well-being of his patients. The contrasting fieldworker did not always appear at his clinics; when he did, his

Received for publication 12 December, 1977. 
behaviour towards patients was abrupt and authoritarian. Defaulters from his clinics, and even patients who continued to attend had built up grudges against the man. He did not seriously attempt to give health education or to motivate patients to ingest medicine punctually. If one endeavours to characterize the leprosy treatment available at clinics throughout the WKLCP, one must admit that the inferior LPW was more typical than his colleague.

Apart from the question of how regularly patients attended their clinics and received their monthly allotment of diaminodiphenyl sulphone (DDS), essential doubt remained whether they swallowed their DDS faithfully as instructed between clinic dates at home. Urine analysis of patients who were "regular attenders" at clinics in Malawi, Ethiopia and Tanzania has shown that such regularity does not guarantee satisfactory intake of DDS without supervision at home (Ellard et al., 1974b; Low and Pearson, 1974; Huikeshoven et al., 1976). Would tine same pattern emerge from analysis of the urine of the "regular attenders" of the superior LFW in the Wangas? Or would the extra attention which he devoted to health education and patient motivation prove sufficient to produce satisfactory at-home DDS swallowing patterns? Ideally, such urine analysis would also have been conducted among regular attenders at the clinics of the second fieldworker in the Wangas. Collection of urine took place, however, several months after the conclusion of sociological research. In the interim the second fieldworker had died and his clinics, after a period of disruption, had been entrusted to a public health technician whose merits were not yet known. Differences or similarities in the DDS content in patients' urine samples would thus have been impossible to interpret.

\section{Methods}

\section{COLLECTION OF URINE SAMPLES}

Urine samples were collected by 2 interpreters employed earlier during the sociological research project. They now worked under the supervision of senior staff at Alupe Leprosy Hospital. All patients treated by the superior fieldworker who had been part of the sociological research sample and who were scheduled to receive $300 \mathrm{mg}$ DDS/week were visited. This sample had been selected to be representative (age, sex, degree of deformity, registration at tree clinic* or health centre) of leprosy patient caseloads in Western Province. Additional patients of the same fieldworker receiving $300 \mathrm{mg}$ DDS/week were chosen at random from all his clinics which brought the total of urine samples to 39: 17 from men, 22 from women. Surprise visits were the occasion for collection, 2 days after scheduled home medication. No reason was offered to patients to explain why their urine was wanted.

\section{ANAL YSIS OF URINE SAMPLES}

The samples were analysed for their DDS/creatinine ratio in keeping with the method described by Ellard et al. (1974a). Samples thus examined were evaluated according to the positive/negative classification laid down in Huikeshoven et al. (1976), based on comparison with urine from 65 supervized

\footnotetext{
* This is a clinic held in the open under a mango tree.
} 
patients and 62 blank controls from Tanzania. Urine samples with a DDS/creatinine ratio greater than 10.0 (male) or 12.0 (female) were classified as positive.

\section{Results}

Table 1 summarizes the ratios of DDS/creatinine found in the 39 urine samples examined, compared to blank, control and field statistics calculated for urine samples in Mwanza, Tanzania (Huikeshoven et al., 1976).

TABLE 1

DDS/creatinine ratios in urine samples

\begin{tabular}{|c|c|c|c|c|c|}
\hline \multirow{2}{*}{\multicolumn{2}{|c|}{ Type of urine samples }} & \multirow{2}{*}{ Number } & \multirow{2}{*}{$\%$} & \multicolumn{2}{|c|}{ DDS/creatinine $(\mu \mathrm{g} / \mathrm{mg})$} \\
\hline & & & & Range & Mean $\pm S_{\mathrm{m}}$ \\
\hline \multicolumn{6}{|c|}{ From men } \\
\hline Blanks & & 32 & - & $1.4-9.8$ & $5.3 \pm 0.5$ \\
\hline \multicolumn{2}{|c|}{ 2nd day supervized } & 32 & - & $14.8-68.8$ & $50.1 \pm 2.0$ \\
\hline & Field samples $<10$ (negative) & 4 & 24 & $5.0-\quad 9.5$ & $7.8 \pm 1.0$ \\
\hline \multirow[t]{2}{*}{ Wanga } & $\{$ Field samples $>10$ (positive) & 13 & 76 & $11.4-70.8$ & $49.6 \pm 4.4$ \\
\hline & All field samples & 17 & 100 & $5.0-70.8$ & $39.8 \pm 5.5$ \\
\hline & (Field samples < 10 (negative) & 21 & 26 & $2.6-9.9$ & $6.4 \pm 0.5$ \\
\hline \multirow[t]{2}{*}{ Mwanza } & $\{$ Field samples $>10$ (positive) & 59 & 74 & $10.4-88.3$ & $38.8 \pm 2.5$ \\
\hline & All field samples & 80 & 100 & $2.6-88.3$ & $30.3 \pm 2.4$ \\
\hline \multicolumn{6}{|c|}{ From women } \\
\hline Blanks & & 30 & - & $0.0-12.5$ & $6.0 \pm 0.5$ \\
\hline \multicolumn{2}{|c|}{ 2ndday supervized } & 33 & - & $38.9-107.6$ & $64.9 \pm 0.3$ \\
\hline & Field samples $<12$ (negative) & 2 & 9 & $10.7-11.9$ & $11.3 \pm 0.6$ \\
\hline \multirow[t]{2}{*}{ Wanga } & Field samples $>12$ (positive) & 20 & 91 & $12.1-125.4$ & $63.3 \pm 5.7$ \\
\hline & All field samples & 22 & 100 & $10.7-125.4$ & $58.6 \pm 6.1$ \\
\hline \multirow{3}{*}{ Mwanza } & Field samples < 12 (negative) & 27 & 35 & $0.0-11.6$ & $6.9 \pm 0.6$ \\
\hline & $\{$ Field samples $>12$ (positive) & 51 & 65 & $12.5-105.8$ & $43.4 \pm 2.9$ \\
\hline & All field samples & 78 & 100 & $0.0-105.8$ & $30.8 \pm 2.9$ \\
\hline
\end{tabular}

Indicated are percentages of positive and negative results, ranges of values found in each group, and mean values with the standard error of the mean $\left(S_{\mathrm{m}}\right)$ for each group.

As a consequence of the limited number of urine samples from the Wangas, the $S_{\mathrm{m}}$ values are considerable. Results should therefore be interpreted with caution. Statistical analysis reveals, however, that the difference between the mean ratio found in positive urine samples from Wanga men and from Mwanza men is, apparently, significant. On the other hand the difference between the mean ratio found in all urine samples from Wanga men and from Mwanza men is not clearly significant and the difference between the percentages of positive results in both male groups is clearly not significant. Differences found between the urine samples of the 2 female groups, however, is much more convincing: the means of positive samples, the means of all samples, and the percentages of positive results all display significant differences in favour of the Wanga women $(P<0.005)$.

One is also able to estimate the total quantity of DDS swallowed compared to the doses distributed at clinics (Ellard et al., 1974b). Such comparison is 
illustrated in Table 2. Results from similar proceedings in Tanzania are once again included. The difference between results of Wanga men (77\%) and Mwanza men $(56 \%)$ is almost significant $(P<0.10)$. The difference between results of Wanga women (89\%), however, and Mwanza women (42\%) is definitely significant $(P<0.001)$.

TABLE 2

Estimated amount of DDS swallowed, relative to the amount received at clinics

\begin{tabular}{|c|c|c|}
\hline Origin & Men & Women \\
\hline $\begin{array}{l}\text { Wanga } \\
\text { Mwanza }\end{array}$ & $\begin{array}{l}77 \% \pm 13 \% \\
56 \% \pm 6 \%\end{array}$ & $\begin{array}{l}89 \% \pm 10 \% \\
42 \% \pm 5 \%\end{array}$ \\
\hline
\end{tabular}

A most interesting picture is obtained comparing Wanga and Mwanza results by means of the frequency distributions of recorded DDS/creatinine ratios (Fig. 1). Figure 1 shows with clarity that for both men and women the positive urine samples from the Wangas have frequency distributions which closely resemble those of supervized groups, whereas positive urine samples from Mwanza do not. The general conclusion appears valid that urine samples from the Wangas indicate more systematic swallowing of correct doses of DDS than was true in Mwanza.

Lastly, a few remarks should be made concerning the $6 \mathrm{~W}$ anga patients whose urine samples proved negative upon analysis. First, 5 of them achieved a result close to the positive border. This suggests that either they took some DDS on the proper day, or even all their prescribed medicine $(300 \mathrm{mg})$ during the preceding week. Second, inclusion of the majority of patients whose urine was tested in the sample studied during prior sociological research meant that more information concerning them was available at the time of the urine analysis than merely their names! Participation of those who collected the urine samples in the sociological research project turned out to have distinct advantages: they were all able to make notes concerning the home circumstances of patients they visited to collect urine (illnesses, births, deaths, leprosy reactions, etc.) which helped suggest explanations why 5 of the 6 patients whose urine tested negatively had skipped, wholly or in part, taking their medicine as scheduled (Bijleveld, 1977)

\section{Discussion}

Results of the analysis of urine samples from regular attenders at the clinics of a superior leprosy fieldworker in the Wangas confirm the relatively high quality of his job performance. Not only do his patients come to clinics more dependably than most patients in Western Province, but they take their DDS at home with commendable regularity compared with regular attenders at clinics in Mwanza, Tanzania. Because a profile of patients whose urine was 


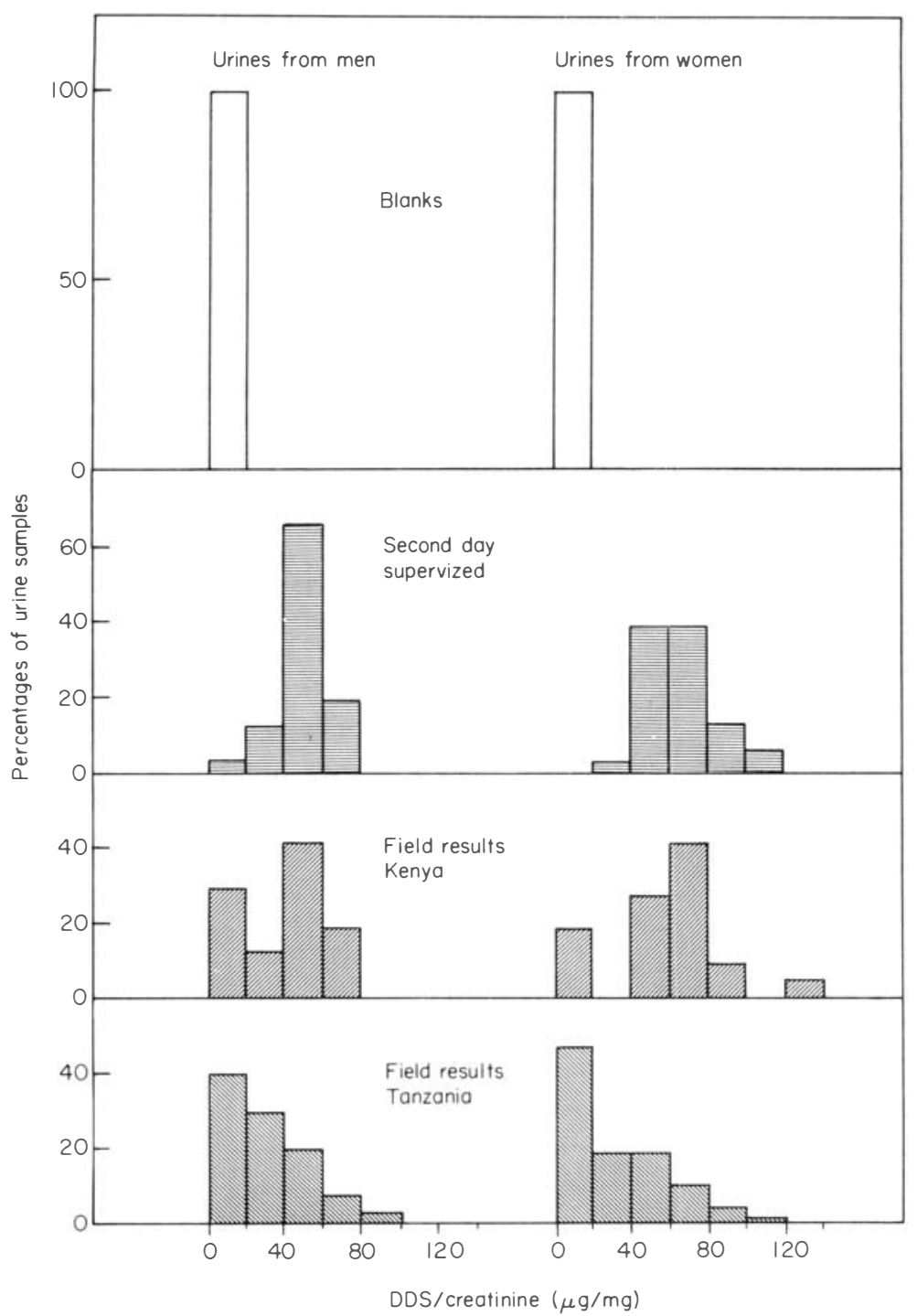

Fig. 1. Frequency distribution of DDS/creatinine ratios.

tested in the Wangas had been compiled previously, moreover, plausible explanations could be advanced why the few patients whose urine tested negatively had, atypically, missed their full medication the week of urine collection. Results also indicate how meaningfully social scientific and physical research can complement each other. 


\section{Acknowledgments}

The authors wish to express their gratitude to Ali Okumu and James Hawkins Okumu who collected urine samples, to Dr Jan Broekman who supervized their collection and transport, and to Alida Timmer who analysed them. Donald Bloch kindly helped in preparation of the English text. For this study financial support was received from the Netherlands Leprosy Relief Association.

\section{References}

Bijleveld, I. (1976). Leprosy and Other Diseases in the Three Wangas: Community Thought Patterns About Health Care and Their Consequence for Emergent Patients. (Available from the Netherlands Leprosy Relief Association.)

Bijleveld, I. (1977). Leprosy Care: Patients' Expectations and Experiences. (Available from the Netherlands Leprosy Relief Association.)

Ellard, G. A., Gammon, P. T., Helmy, H. S. and Rees, R. J. W. (1974a). Urine tests to monitor the self-administration of dapsone by leprosy patients. Am. J. trop. Med. Hyg. 23, 464.

Ellard, G. A., Gammon, P. T. and Harris, J. M. (1974b). The application of urine tests to monitor the regularity of dapsone self-administration. Lepr. Rev. 45, 224.

Huikeshoven, H. C. J., Honhoff, C., van Eys, G. J. J. M., Anten, J. G. F., Mayer, J. M. A. and van Helden, H. P. T. (1976). Weekly self-medication of leprosy patients monitored by DDS/creatinine ratios in urines. Lepr. Rev. 47, 201.

Low, S. J. M. and Pearson, J. M. H. (1974). Do leprosy patients take dapsone regularly? Lepr. Rev. 45, 218.

Varkevisser, C. M., in co-operation with Risseeuw, C. I. and Bijleveld, I. (1977). Integration of Combined Leprosy and Tuberculosis Services within the General Health Care Delivery System Western Province, Kenya. (Available from the Netherlands Leprosy Relief Association.) 